\title{
Safety evaluation on low-molecular-weight hydroxyethyl starch for volume expansion therapy in pediatric patients: a meta-analysis of randomized controlled trials
}

\author{
Lixia $\mathrm{Li}^{1+}$, Yongyang $\mathrm{Li}^{2+}$, Xiaoxing $\mathrm{Xu}^{3}$, Bo Xu' ${ }^{4}$, Rongrong Ren ${ }^{4}$, Yan $\mathrm{Liu}^{1}$, Jian Zhang ${ }^{1^{*}}$ and Bin $\mathrm{He}^{4^{*}}$
}

\begin{abstract}
Introduction: Hydroxyethyl starch (HES) has been widely used for volume expansion, but its safety in adult patients has been questioned recently. The aim of this meta-analysis is to see whether or not HES has any adverse effect in pediatric patients.

Methods: Randomized controlled trials (RCTs) involving pediatric patients who received $6 \%$ low-molecular-weight HES, published before January 2014, were searched for in Pubmed, Embase database and Cochrane Library. Two reviewers independently extracted the valid data, including the mortality, renal function, coagulation, blood loss, hemodynamic changes, and length of hospital and ICU stay. All data were analyzed by $P^{2}$-test, and the results of statistical analysis were displayed in forest plots. Possible publication bias was tested by funnel plots. Bayesian analysis was performed using WinBUGS with fixed and random effects models.

Results: A total of $13 \mathrm{RCTs}$ involving 1,156 pediatric patients were finally included in this meta-analysis. Compared with other fluids, HES did not significantly decrease the mortality (RR $=-0.01 ; 95 \% \mathrm{Cl}: 0.05$ to $\left.0.03 ; P=0.54 ; P^{2}=6 \%\right)$, creatinine level ( $P^{2}$-test: $\mathrm{MD}=1.81 ; 95 \% \mathrm{Cl}$ : -0.35 to $3.98 ; P=0.10 ;{ }^{2}=0 \%$; Bayesian analysis: Fixed effect model $\mathrm{MD}=1.77$; 95\%Cl: -0.07 to 3.6; Random effects model $\mathrm{MD}=1.78 ; 95 \% \mathrm{Cl}:-1.86$ to 5.33 ), activated partial thromboplastin time $\left(\mathrm{MD}=0.01 ; 95 \% \mathrm{Cl}:-1.05\right.$ to $\left.1.07 ; P=0.99 ; P^{2}=42 \%\right)$, and blood loss (MD $=17.72 ; 95 \% \mathrm{Cl}:-41.27$ to $\left.5.82 ; P=0.10 ; P^{2}=0 \%\right)$ in pediatric patients. However, HES significantly decreased the blood platelet count $(\mathrm{MD}=20.99 ; 95 \% \mathrm{Cl}:-32.08$ to -9.90 ; $\left.P=0.0002 ; P^{2}=28 \%\right)$ and increased the length of ICU stay (MD $=0.94 ; 95 \% \mathrm{Cl}: 0.18$ to $\left.1.70 ; P=0.02 ; P^{2}=46 \%\right)$.

Conclusions: Volume expansion with $6 \%$ HES significantly decreased the platelet count and increased the length of ICU stay, also might have an adverse effect on renal function. Therefore HES is not recommended for pediatric patients, which safety needs more high quality RCTs and studies to confirm in future.
\end{abstract}

\section{Introduction}

Hydroxyethyl starch (HES) has been widely used for clinical volume expansion since the 1960s. However, a series of recent randomized controlled trials (RCTs) [1-3] have questioned the safety of HES for volume expansion in adult patients, suggesting that HES may increase the mortality

\footnotetext{
*Correspondence: zj_boss@126.com; hebinicu@139.com

${ }^{\dagger}$ Equal contributors

'Department of Pharmacy, Xinhua Hospital, Shanghai Jiaotong University School of Medicine, Kongjiang Road 1665, Shanghai 200092, China

${ }^{4}$ Department of Anesthesiology and SICU, Xinhua Hospital, Shanghai Jiaotong University School of Medicine, Kongjiang Road 1665, Shanghai 200092, China

Full list of author information is available at the end of the article
}

and the incidence of renal replacement therapy. Based on these studies, the European Society of Intensive Care Medicine (ESICM) recommends that HES should not be used for volume expansion due to the high risk for inducing kidney injury and bleeding [4]. However, this recommendation is mainly based on the findings in adult patients. Whether HES has similar adverse effects in pediatric patients and whether it can be used safely in children remain unanswered, knowing that children have different pulmonary, vascular and cardiac compliances, and different responses to volume expansion therapy as compared with adult patients [5-7]. The objective of this meta-analysis was to

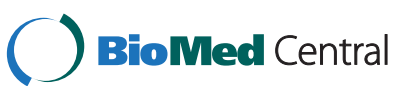


evaluate the safety of HES versus other fluids for plasma volume expansion in pediatric patients.

\section{Materials and methods}

No ethical approval was required because this study includes no confidential personal data or interventions on the patients according to the Preferred Reporting Items for Systematic Reviews and Meta-Analyses (PRISMA) [8]. Bayesian analysis on creatinine $(\mathrm{Cr})$ was performed using WinBUGS (version 1.4.3, MRC Biostatistics Unit, Cambridge, UK) with fixed and random effects models developed by Dias [9]. We used 100,000 iterations after an initial burn-in of 1,000 . This meta-analysis included RCTs for pediatric patients who received 6\% low-molecularweight HES. The primary parameters were the overall mortality, renal function, bleeding and coagulation function. The secondary parameters were hemodynamic parameters, the amount of fluid used for resuscitation, and the length of hospital and ICU stay. The inclusion criteria were: 1 ) RCTs; 2) patients $\leq 18$ years old; and 3) studies that included a group of patients receiving 6\% lowmolecular-weight (130 kD and $200 \mathrm{kD}$ ) HES and a control group receiving other fluids. RCTs that met one of the following criteria were excluded: 1) no group receiving $6 \%$ low-molecular-weight HES; 2) no valid data available; and 3) studies from Dr. Joachim Boldt.

\section{Search strategies}

We searched the PubMed and Embase databases and the Cochrane Library using the following key words and related free words: 'hydroxyethyl starch', 'HES', 'child', 'children' and 'pediatric'. The relevant clinical trials were those published before 19 January 2014 that met the above criteria. The search was limited to 'randomized controlled trials', 'human' and 'children', and the language was restricted to English. The details are shown in Additional file 1.

\section{Study selection and data extraction}

Two reviewers (LL and YL) independently screened the search results and obtained the full texts according to the inclusion and exclusion criteria, and independently extracted the valid data. Data extraction and analysis were performed under the supervision of an experienced statistician (XX).

\section{Quality assessment}

The literature quality was assessed by the Jadad scoring system [10]. A study with an overall score $\leq 2$ was considered poor in quality and $>2$ was considered high in quality. We performed risk of bias assessment using the 'Risk of bias' tool in the Cochrane Handbook for Systematic Reviews of Interventions [11]. We assessed each study according to the quality domains of random sequence generation, allocation concealment, blinding of participants and personnel, incomplete outcome data, selective outcome reporting and other bias.

\section{Statistical analysis}

Data were analyzed by Review Manager (5.2 RevMan, Cochrane Collaboration). The pooling continuous effect data were assessed by mean difference (MD). When median and extreme values were presented in the original articles, these data were converted into mean and standard deviation according to relevant formulas [12]. Pooling non-continuous data were assessed by the risk ratio (RR). If there was more than one group, data were pooled as one group. Statistical heterogeneity of the data was analyzed quantitatively by the $I^{2}$-test [13]. The fixed effects model was selected if no heterogeneity existed $\left(I^{2}<50 \%\right)$, and the random effects model was selected in the event of $50 \% \leq I^{2}<75 \%$. A sensitivity analysis or subgroup analysis would be performed to exclude the heterogeneity if $I^{2} \geq 75 \%$; otherwise only descriptive analysis would be performed without meta-analysis. Publication bias was tested by funnel plots. Two-sided tests were performed with a significant difference at $P<0.05$.

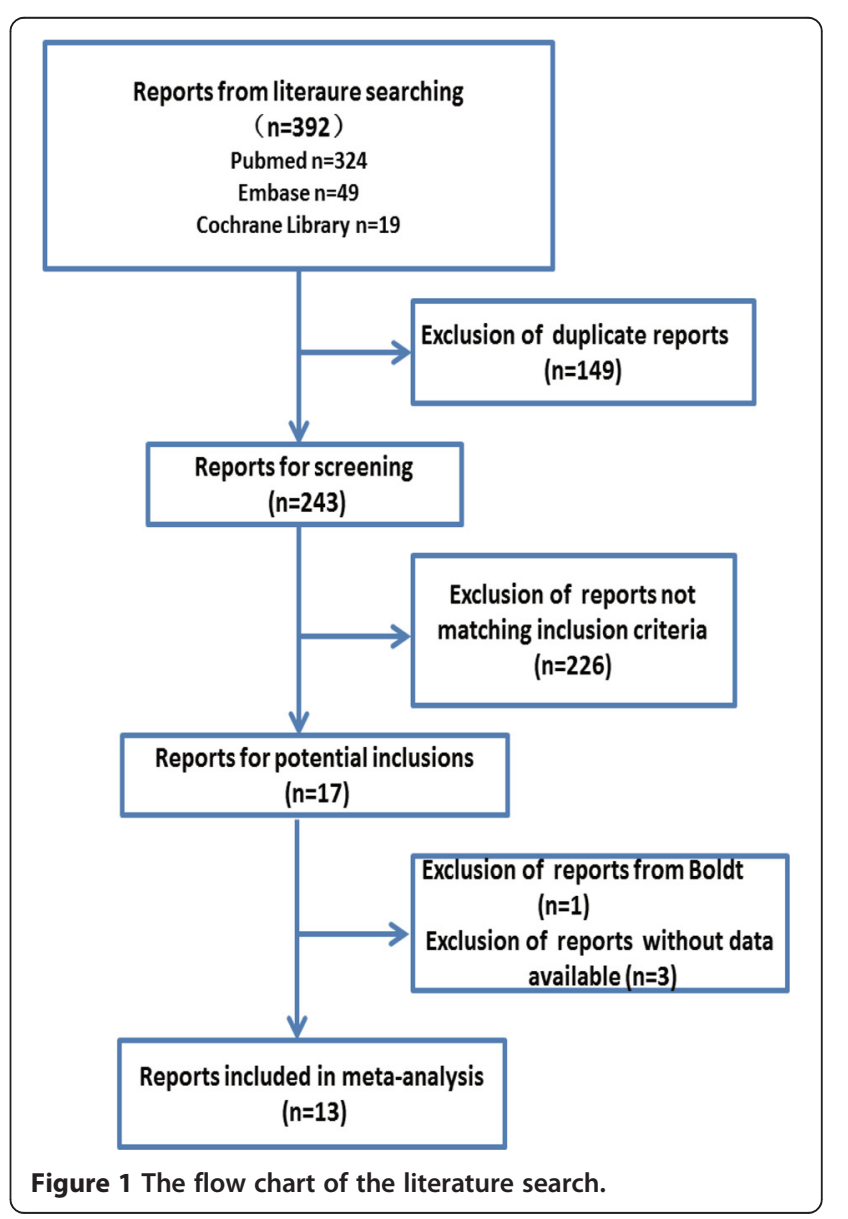


Table 1 Characteristics of the included randomized controlled trials

\begin{tabular}{|c|c|c|c|c|c|c|c|c|c|}
\hline \multirow[t]{2}{*}{ Trial } & \multirow[t]{2}{*}{ Indication } & \multicolumn{4}{|l|}{ HES group } & \multicolumn{4}{|l|}{ Control group } \\
\hline & & Program & $\begin{array}{l}\text { Patients } \\
\text { (n) }\end{array}$ & Age & Weight (kg) & Program & Patients (n) & Age & Weight (kg) \\
\hline \multirow[t]{2}{*}{ Liet et al. 2006 [14] } & \multirow{2}{*}{$\begin{array}{l}\text { Hypotensive neonates with low cardiac } \\
\text { output and absence of myocardial } \\
\text { dysfunction }\end{array}$} & \multirow[t]{2}{*}{$6 \% H E S$ 200/0.5 } & \multirow[t]{2}{*}{7} & \multirow[t]{2}{*}{$5 \pm 6 d$} & \multirow[t]{2}{*}{$1.4 \pm 0.7$} & \multirow{2}{*}{$\begin{array}{l}5 \% \text { Albumin } \\
\text { Isotonic saline }\end{array}$} & 7 & $2 \pm 1 d$ & $1.3 \pm 0.6$ \\
\hline & & & & & & & 7 & $6 \pm 10 d$ & $0.9 \pm 0.3$ \\
\hline Standl et al. 2008 [15] & Non-cardiac surgery & $6 \%$ HES 130/0.4 & 41 & $8.3 \pm 9.2 \mathrm{~m}$ & $8.0 \pm 6.6$ & $5 \%$ Albumin & 40 & $8.7 \pm 10.9 \mathrm{~m}$ & $7.1 \pm 4.6$ \\
\hline Akech et al. 2010 [16] & Severe falciparum malaria & $6 \%$ HES $130 / 0.4$ & 40 & $40.3 \pm 12.8 \mathrm{~m}$ & - & $6 \%$ Dextran & 39 & $40.3 \pm 12.8 \mathrm{~m}$ & - \\
\hline Van Der Linden et al. 2013 [17] & $\begin{array}{l}\text { Undergoing elective surgery for } \\
\text { congenital heart disease }\end{array}$ & $6 \% H E S$ 130/0.4 & 31 & $6.1 \pm 5.2 Y$ & $25.1 \pm 24.6$ & $5 \%$ Albumin & 29 & $4.8 \pm 3.7 y$ & $16.7 \pm 10.3$ \\
\hline Liet et al. 2003 [18] & $\begin{array}{l}\text { Plasma volume expansion with HES } \\
\text { in the newborn }\end{array}$ & 6\% HES 200/0.5 & 13 & $3 \pm 2.2 d$ & $1.27 \pm 0.47$ & $5 \%$ Albumin & 13 & $5 \pm 3 d$ & $1.33 \pm 0.64$ \\
\hline Hanart et al. 2009 [19] & $\begin{array}{l}\text { Undergoing cardiac surgery with } \\
\text { cardiopulmonary bypass }\end{array}$ & 6\%HES 130/0.4 & 60 & $23.5 \pm 19.8 \mathrm{~m}$ & $9 \pm 4$ & $4 \%$ Albumin & 59 & $17.3 \pm 20.0 \mathrm{~m}$ & $8 \pm 4.3$ \\
\hline Akkucuk et al. 2013 [20] & Children undergoing cardiac surgery & $6 \% H E S$ 130/0.4 & 12 & $3.9 \pm 1.7 y$ & $13.5 \pm 4.5$ & Ringer's acetate & 12 & $5.1 \pm 3.7 y$ & $16.2 \pm 8.8$ \\
\hline Chong Sung et al. 2006 [21] & $\begin{array}{l}\text { Undergoing elective repair of atrial } \\
\text { septal defect, ventricular septal defect } \\
\text { or tetralogy of Fallo }\end{array}$ & 6\%HES $130 / 0.4$ & 21 & $31.5 \pm 34.6 \mathrm{~m}$ & $13.7 \pm 8.9$ & Fresh frozen plasma & 21 & $43.5 \pm 61.6 \mathrm{~m}$ & $15.7 \pm 13.4$ \\
\hline \multirow[t]{2}{*}{ Haas et al. 2007 [22] } & \multirow{2}{*}{$\begin{array}{l}\text { Prevention of intra-operative } \\
\text { hypovolemia }\end{array}$} & \multirow[t]{2}{*}{ 6\% HES $130 / 0.4$} & \multirow[t]{2}{*}{14} & \multirow[t]{2}{*}{$9 \pm m$} & \multirow[t]{2}{*}{$9 \pm 2$} & \multirow{2}{*}{$\begin{array}{l}5 \% \text { Albumin } \\
4 \% \text { Gelatine }\end{array}$} & 14 & $14 \pm 9 m$ & $10 \pm 2$ \\
\hline & & & & & & & 14 & $10 \pm 10 m$ & $8 \pm 3$ \\
\hline \multirow[t]{2}{*}{ Wills et al. 2005 [23] } & \multirow[t]{2}{*}{ Dengue shock syndrome } & \multirow[t]{2}{*}{$6 \%$ HES 200/0.5 } & \multirow[t]{2}{*}{129} & \multirow[t]{2}{*}{$9.6 \pm 4.9 y$} & \multirow[t]{2}{*}{$26 \pm 13.3$} & \multirow{2}{*}{$\begin{array}{l}\text { 5\% Dextran } \\
\text { Ringer's lactate }\end{array}$} & 126 & $10 \pm 4.1 y$ & $27 \pm 14.5$ \\
\hline & & & & & & & 128 & $9.8 \pm 4.6 y$ & $26.8 \pm 13.9$ \\
\hline Wills et al. 2005 [23] & Dengue shock syndrome & $6 \% H E S$ 200/0.5 & 62 & $9.3 \pm 4.6 y$ & $24.8 \pm 14.1$ & $5 \%$ Dextran & 67 & $8.8 \pm 4.6 y$ & $25.5 \pm 13.4$ \\
\hline Sahoo et al. 2007 [24] & $\begin{array}{l}\text { with CCHD undergoing modified } \\
\text { BT shunt operations }\end{array}$ & $6 \% H E S$ 200/0.5 & 25 & $17.7 \pm 12.3 \mathrm{~m}$ & $7.0 \pm 2.4$ & $5 \%$ Dextran & 25 & $19.5 \pm 14.3 \mathrm{~m}$ & $7.9 \pm 2.4$ \\
\hline Osthaus et al. 2009 [25] & $\begin{array}{l}\text { Aged } 0 \text { to } 12 \text { years scheduled } \\
\text { for surgery }\end{array}$ & $6 \% H E S$ 130/0.4 & 25 & $4.4 \pm 6.4 y$ & $18.7 \pm 22.2$ & $4 \%$ Gelatin & 25 & $4.6 \pm 6.3 y$ & $20.2 \pm 25.0$ \\
\hline \multirow[t]{2}{*}{ Witt et al. 2008 [26] } & \multirow[t]{2}{*}{ Major pediatric surgery } & $6 \% \mathrm{HES}$ & \multirow[t]{2}{*}{25} & \multirow[t]{2}{*}{$33.2 \pm 40 \mathrm{~m}$} & \multirow[t]{2}{*}{$13.4 \pm 11$} & \multirow[t]{2}{*}{ 4\%Gelatin } & \multirow[t]{2}{*}{25} & \multirow[t]{2}{*}{$38.7 \pm 39 \mathrm{~m}$} & \multirow[t]{2}{*}{$14.2 \pm 10$} \\
\hline & & $130 / 0.4$ & & & & & & & \\
\hline
\end{tabular}


Table 2 Assessment of literature quality

\begin{tabular}{|c|c|c|c|c|c|c|}
\hline $\begin{array}{l}\text { Literature } \\
\text { resources }\end{array}$ & Randomization & $\begin{array}{l}\text { Random sequence } \\
\text { generation }\end{array}$ & $\begin{array}{l}\text { Allocation } \\
\text { concealment }\end{array}$ & $\begin{array}{l}\text { Blinding } \\
\text { methodology }\end{array}$ & $\begin{array}{l}\text { Withdrawal } \\
\text { and dropouts }\end{array}$ & $\begin{array}{l}\text { Jadad } \\
\text { score }\end{array}$ \\
\hline Liet et al. 2006 [14] & Yes & Computer-generated & Yes & Yes & $6 / 0$ & 5 \\
\hline Standl et al. 2008 [15] & Yes & Sealed randomization envelopes & Yes & None & $13 / 1$ & 4 \\
\hline Akech et al. 2010 [16] & Yes & Randomization cards & Yes & Unclear & $16 / 0$ & 4 \\
\hline Van Der Linden et al. 2013 [17] & Yes & $\begin{array}{l}\text { By means of a macro written in } \mathrm{SAS}^{\oplus} \text {, } \\
\text { version 9.3.1. }\end{array}$ & Yes & Double-blinded & $0 / 0$ & 5 \\
\hline Liet et al. 2003 [18] & Yes & Unclear & Unclear & Double-blinded & Unclear & 2 \\
\hline Hanart et al. 2009 [19] & Yes & $\begin{array}{l}\text { The randomization assignment was } \\
\text { concealed in an envelope }\end{array}$ & Yes & Double-blinded & Unclear & 4 \\
\hline Akkucuk et al. 2013 [20] & Yes & Unclear & Unclear & Unclear & Unclear & 1 \\
\hline Chong Sung et al. 2006 [21] & Yes & Unclear & Unclear & Unclear & Unclear & 1 \\
\hline Haas et al. 2007 [22] & Yes & Unclear & Unclear & Unclear & Unclear & 1 \\
\hline Wills et al. 2005 [23] & Yes & Computer-generated & Yes & Yes & $0 / 1$ & 5 \\
\hline Sahoo et al. 2007 [24] & Yes & Unclear & Unclear & Unclear & $0 / 7$ & 2 \\
\hline Osthaus et al. 2009 [25] & Yes & Computer-generated & Unclear & None & Unclear & 2 \\
\hline Witt et al. 2008 [26] & Yes & Unclear & Unclear & None & Unclear & 1 \\
\hline
\end{tabular}

\section{Results}

Literature search and study selection

Figure 1 is the flow chart of the literature search, which identified a total of 392 articles, from which 379 were excluded after reading the titles, abstracts and full texts. Finally, 13 RCTs were included in this meta-analysis.

\section{Characteristics of the articles}

The characteristics of the 13 RCTs, involving 1,156 patients, are shown in Table 1. Four RCTs [14-17] reported the mortality; five RCTs [14,17-20] reported the effect on renal function; nine RCTs [15,17-19,21-25] reported the effects on bleeding and coagulation; seven RCTs
[14-17,19,25,26] reported hemodynamic changes; six RCTs $[15,17,19-21,25]$ reported the amount of fluid replacement; four RCTs $[15,17,19,20]$ reported the length of ICU stay; and four RCTs $[15,19,20,23]$ reported the total length of hospital stay.

\section{Quality of the included studies}

As shown in Table 2, the study quality was assessed using the Jadad scoring system. Seven RCTs were of low quality $(\leq 2)$ and six RCTs were of high quality $(>2)$. More details about the risk of bias assessment are shown in Table 3. The overall risk of bias in four RCTs was low, and that in the other RCTs was unclear.

Table 3 The assessment risk of bias

\begin{tabular}{|c|c|c|c|c|c|c|c|}
\hline Study & $\begin{array}{l}\text { Sequence } \\
\text { generation }\end{array}$ & $\begin{array}{l}\text { Allocation } \\
\text { concealment }\end{array}$ & $\begin{array}{l}\text { Blinding of participants, } \\
\text { personnel and outcome } \\
\text { assessors }\end{array}$ & $\begin{array}{l}\text { Incomplete } \\
\text { outcome data }\end{array}$ & $\begin{array}{l}\text { Selective outcome } \\
\text { reporting }\end{array}$ & $\begin{array}{l}\text { Other } \\
\text { bias }\end{array}$ & $\begin{array}{l}\text { Overall risk } \\
\text { of bias }\end{array}$ \\
\hline Liet et al. 2006 [14] & Low & Low & Low & Low & Low & Low & Low \\
\hline Standl et al. 2008 [15] & Low & Low & Unclear & Low & Low & Low & Unclear \\
\hline Akech et al. 2010 [16] & Low & Low & Unclear & Low & Low & Low & Unclear \\
\hline Van Der Linden et al. 2013 [17] & Low & Low & Low & Low & Low & Low & Low \\
\hline Liet et al. 2003 [18] & Unclear & Unclear & Low & Low & Low & Low & Unclear \\
\hline Hanart et al. 2009 [19] & Low & Low & Low & Low & Low & Low & Low \\
\hline Akkucuk et al. 2013 [20] & Unclear & Unclear & Unclear & Low & Low & Low & Unclear \\
\hline Chong Sung et al. 2006 [21] & Unclear & Unclear & Unclear & Low & Low & Low & Unclear \\
\hline Haas et al. 2007 [22] & Unclear & Unclear & Unclear & Low & Low & Low & Unclear \\
\hline Wills et al. 2005 [23] & Low & Low & Low & Low & Low & Low & Low \\
\hline Sahoo et al. 2007 [24] & Unclear & Unclear & Unclear & Low & Low & Low & Unclear \\
\hline Osthaus et al. 2009 [25] & Low & Unclear & Unclear & Low & Low & Low & Unclear \\
\hline Witt et al. 2008 [26] & Unclear & Unclear & Low & Low & Low & Low & Unclear \\
\hline
\end{tabular}




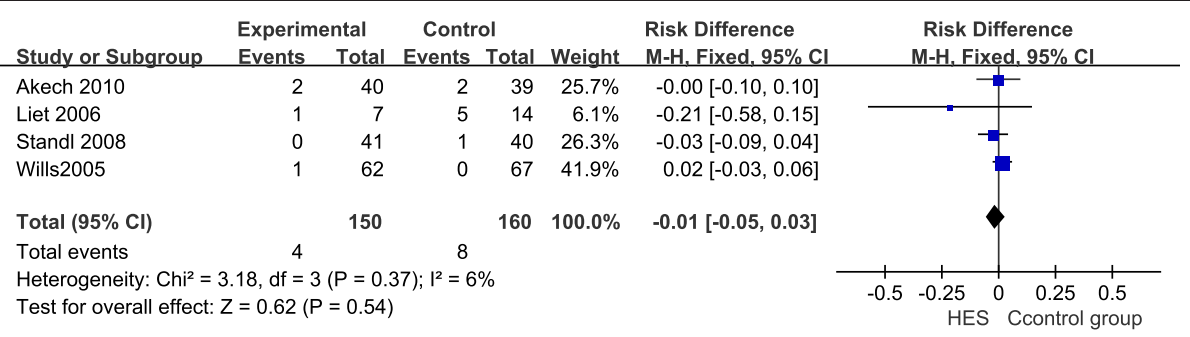

Figure 2 The forest plot of pooled risk ratio for overall mortality. $\mathrm{Cl}$, confidence interval; HES, hydroxyethyl starch; M-H, Mantel-Haenszel.

\section{Overall mortality}

In total, four RCTs reported the overall mortality in 310 pediatric patients, including four deaths in 150 children of the HES group and eight deaths in 160 children of the other fluid groups. There was no significant difference in mortality between the HES group and the other fluid groups $(\mathrm{RR}=-0.01 ; 95 \% \mathrm{CI}$ : -0.05 to $0.03 ; P=0.54$; $I^{2}=6 \%$ ) (Figure 2). Funnel plots showed no publication bias (Additional file 2: Figure S1).

\section{Renal function}

Three RCTs reported Cr change in 205 pediatric patients, including 104 in the HES group and 101 in the control group. The results of statistical analysis showed no significant difference in $\mathrm{Cr}$ between the HES group and the other fluid groups $(\mathrm{MD}=1.81 ; 95 \% \mathrm{CI}$ : -0.35 to 3.98 ; $P=0.10 ; I^{2}=0 \%$ ) (Figure 3 ). Funnel plots showed no publication bias (Additional file 3: Figure S2). Bayesian analysis was performed on $\mathrm{Cr}$ using the fixed and random effects models developed by Dias et al. [9]. The results showed no significant difference between the two groups (fixed effect model $\mathrm{MD}=1.77 ; 95 \% \mathrm{CI}$ : -0.07 to 3.6 ; random effects model $\mathrm{MD}=1.78 ; 95 \% \mathrm{CI}$ : -1.86 to 5.33 ) (Figure 4).

\section{Bleeding and coagulation function}

Seven RCTs reported changes in coagulation function within 24 hours, including 521 pediatric patients (228 in the HES group and 293 in the other fluid groups). We performed subgroup analysis on surgery (five RCTs using $130 \mathrm{kD}$ HES) and non-surgery (two RCTs using $200 \mathrm{kD}$ HES), or different molecular-weight HES. The result showed no significant difference in activated partial thromboplastin time (APTT) between the HES group and the other fluid groups $(\mathrm{MD}=0.01 ; 95 \%$ CI: -1.05 to $1.07 ; P=0.99 ; I^{2}=42 \%$ ) (Figure $5 \mathrm{a}$ ). There was a significant difference in postoperative platelet count $(\mathrm{MD}=-20.99 ; 95 \% \mathrm{CI}:-32.08$ to $-9.90 ; P=0.0002$; $I^{2}=28 \%$ ) (Figure $5 \mathrm{~b}$ ). Four RCTs reported blood loss on the first day post-operation. The result of statistical analysis showed no significant difference in blood loss between the HES group and the other fluid groups $\left(\mathrm{MD}=-9.12 ; 95 \% \mathrm{CI}:-31.06\right.$ to $\left.12.82 ; P=0.42 ; I^{2}=52 \%\right)$ (Figure 5c). Funnel plots showed no publication bias (Additional file 4: Figure S3a, b, c).

\section{Hemodynamics}

Four RCTs reported changes in mean arterial pressure (MAP) and heart rate (HR) on the first day postoperation. The results of statistical analysis showed no significant difference in MAP and HR between the HES group and the other fluid groups (MAP: $\mathrm{MD}=-0.99$; 95\%CI: -3.22 to $1.25 ; P=0.39 ; I^{2}=0 \%$; HR: $\mathrm{MD}=2.37$; 95\%CI:-0.39 to 5.12; $P=0.09 ; I^{2}=0 \%$ ) (Figure 6a, b). Funnel plots showed no publication bias. Three RCTs reported the amount of fluid replacement on the first day post-operation. There was significant heterogeneity within 24 hours of surgery $\left(I^{2}=71 \%\right)$. Given multiple factors that may affect the amount of fluid replacement, we only did descriptive analysis without meta-analysis.

\section{Length of hospital and ICU stay}

Four RCTs reported the length of hospital stay. The results showed no significant difference in the length of hospital stay between the HES group and the other groups $\left(\mathrm{MD}=0.02 ; 95 \% \mathrm{CI}:-0.28\right.$ to $\left.0.31 ; P=0.91 ; I^{2}=0 \%\right)$

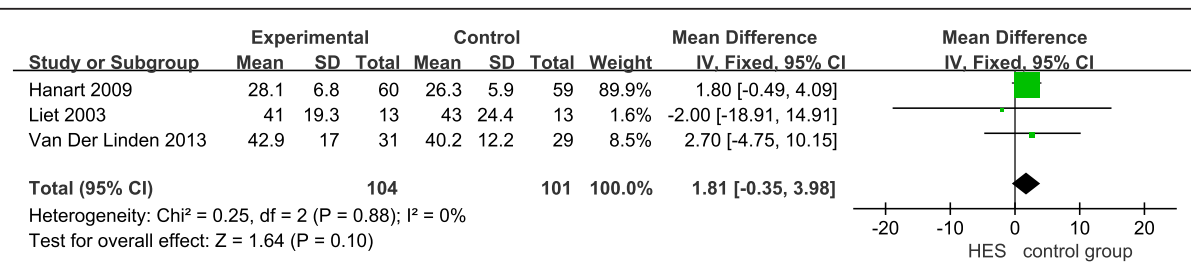

Figure 3 Forest plot of pooled risk ratio for the effect on renal function $\left(l^{2}\right.$-test). Cl, confidence interval; $\mathrm{Cr}$, creatinine; HES, hydroxyethyl starch; IV, inverse variance. 
(Figure 7a). The length of ICU stay in the HES group was longer than that in the other groups $(\mathrm{MD}=0.94 ; 95 \% \mathrm{CI}$ : 0.18 to1.70; $P=0.02 ; I^{2}=46 \%$ ) (Figure $7 \mathrm{~b}$ ). Funnel plots showed no publication bias.

\section{Discussion}

The results of this meta-analysis showed that HES significantly decreased the platelet count and increased the length of ICU stay, and also might have had an adverse effect on renal function. Therefore, it should not be recommended for use in pediatric patients before its safe use in children is confirmed by more high-quality RCTs.

HES might have effects on the mortality of pediatric patients. However, this meta-analysis did not show that HES significantly decreased the mortality of pediatric patients as compared with other fluids, which is consistent with the conclusion made by previous studies in pediatric patients [16,23,27-29]. More findings suggest that HES might have adverse effects on the mortality of adult patients. Sedrakyan et al. [30] reported that the use of HES was linked with a poorer survival as compared with albumin. Trowbridge et al. [31] also reported that elimination of HES was associated with a $67 \%$ decrease in the relative odds of death in patients undergoing cardiopulmonary bypass surgery. There still needs more high quality RCTs and studies to confirm the effect of HES on mortality of pediatric patients in future.

This meta-analysis showed HES might have an adverse effect on renal function, which trend was much stronger. Most studies in adult patients also showed that HES had an adverse effect on renal function. This meta-analysis showed that HES did not decrease the $\mathrm{Cr}$ level in pediatric patients as compared with other fluids. Considering the wide confidence intervals of the result on $\mathrm{Cr}$ and small sample size in the meta-analysis, we cannot conclude that HES is safe in pediatric patients. We used Bayesian analysis to test the possible significant difference. Although compared with previous meta-analysis, Bayesian analysis of the fixed model indicated that the trend was much stronger; the results also showed that there was no significant difference between the two groups. Knowing that many studies reported an association of HES use with an increased incidence of acute kidney injury in adult patients [32-34], it is not unwise to suggest that HES might have adverse effects on renal function and should not be used in pediatric patients with abnormal renal function.

This meta-analysis showed that HES significantly decreased the blood platelet count and might have an adverse effect on the coagulation system in pediatric patients as compared with other fluids, although it did

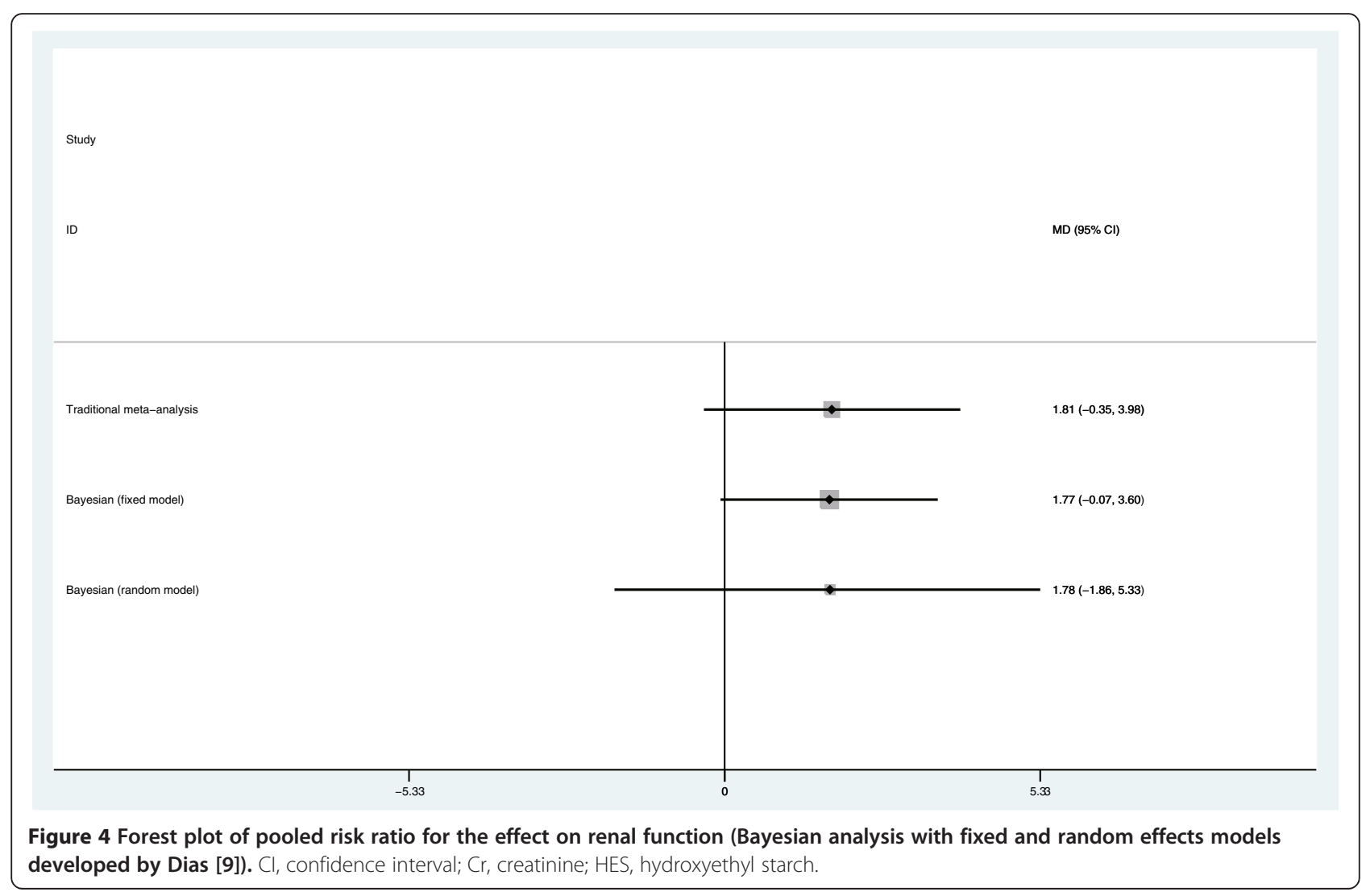


not decrease postoperative blood loss in pediatric patients. Most studies $[15,21,25,35]$ reported that there was no significant change in prothrombin time (PT) and APTT after HES administration in pediatric patients. However, Haas et al. [22] reported that HES prolonged APTT and the blood clotting time and significantly increased the hardness of blood clots. Miller BE et al. [36] also reported that the increased blood loss after cardiopulmonary bypass in pediatric patients may be associated with the use of HES. Coagulation dysfunction is a common cause of excessive bleeding during and after cardiac surgery. Coagulation dysfunction occurring after cardiopulmonary bypass may be partly caused by platelet loss $[37,38]$. Thus, platelet loss is a very important adverse effect on heart surgery. These hemostatic concerns about HES have been further substantiated by a meta-analysis of children and adults receiving HES during cardiac surgery, which showed increased blood loss in the patients receiving HES compared with albumin [39]. The present study showed that HES might have an unfavorable effect on the coagulation system in pediatric patients, especially those who underwent heart surgery.

This meta-analysis showed that HES significantly increased the length of ICU stay. Many studies [40-42] reported the same result on the length of hospital stay between the HES group and other solution groups, but we found no related report on the length of ICU stay in
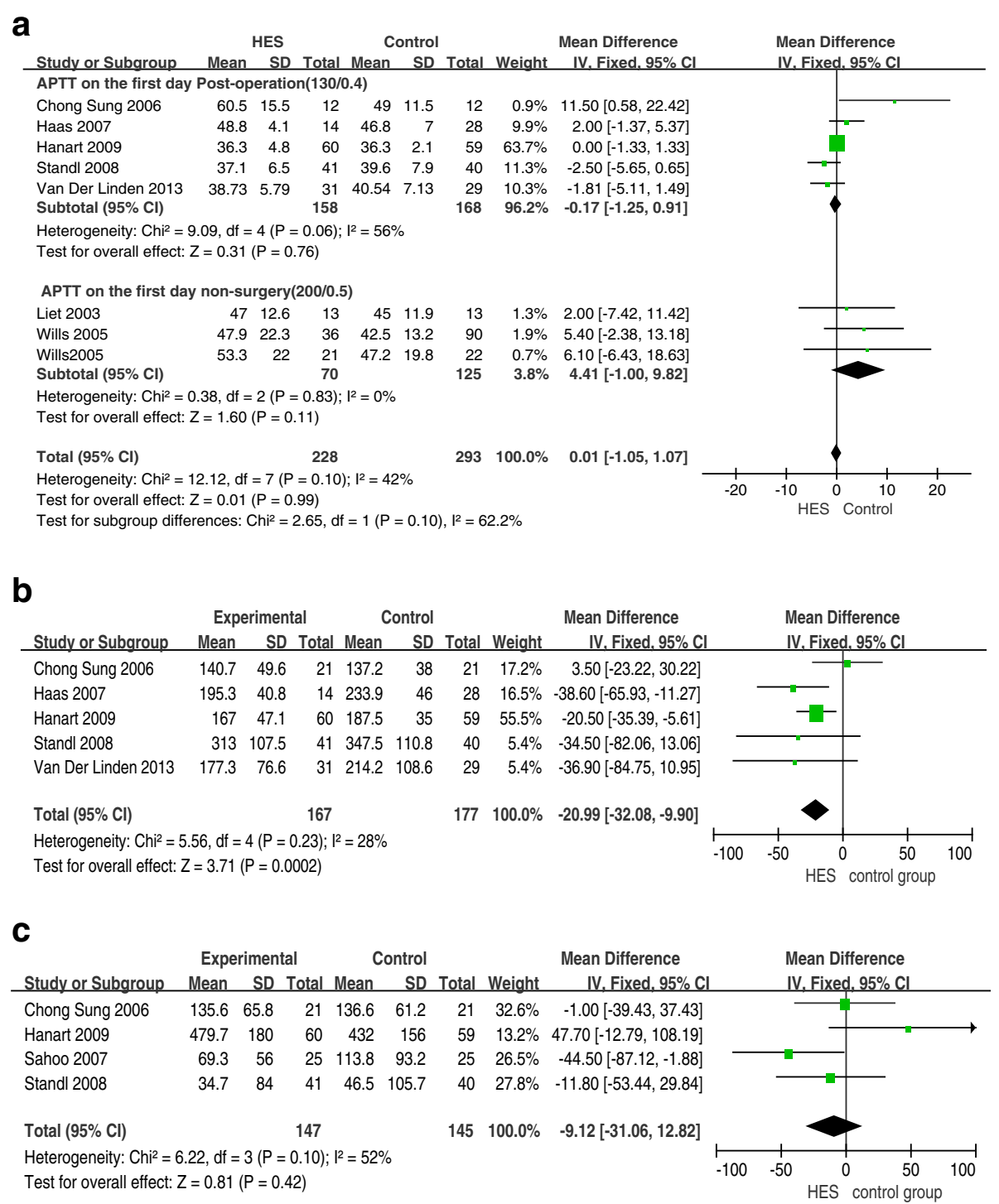

Figure 5 Forest plots of pooled estimates for the effect on coagulation and bleeding. a) activated partial thromboplastin time (APTT). b) Platelet count. c) Blood loss. Cl, confidence interval; HES, hydroxyethyl starch; IV, inverse variance. 
a

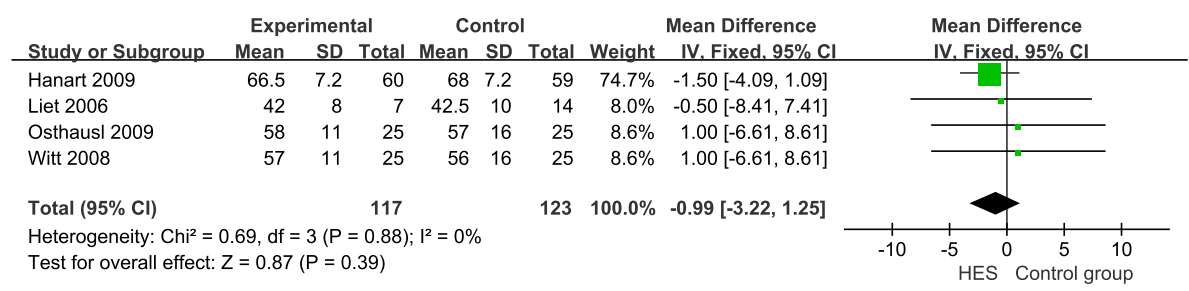

b

\begin{tabular}{|c|c|c|c|c|c|c|c|c|c|}
\hline \multirow[b]{2}{*}{ Study or Subgroup } & \multicolumn{3}{|c|}{ Experimental } & \multicolumn{3}{|c|}{ Control } & \multicolumn{2}{|r|}{ Mean Difference } & \multirow{2}{*}{$\begin{array}{l}\text { Mean Difference } \\
\mid \text { V. Fixed, } 95 \% \mathrm{CI}\end{array}$} \\
\hline & Mean & SD & Total & Mean & SD & Total & Weight & IV, Fixed, $95 \% \mathrm{Cl}$ & \\
\hline Akech 2010 & 168 & 7.1 & 40 & 165 & 7.2 & 39 & $76.3 \%$ & $3.00[-0.15,6.15]$ & \\
\hline Hanart 2009 & 123.8 & 18 & 60 & 125 & 20.5 & 59 & $15.8 \%$ & $-1.20[-8.14,5.74]$ & \\
\hline Liet 2006 & 153 & 17 & 7 & 144 & 16.6 & 14 & $3.2 \%$ & $9.00[-6.30,24.30]$ & \\
\hline Van Der Linden 2013 & 119 & 27.3 & 31 & 119.5 & 23.2 & 29 & $4.6 \%$ & $-0.50[-13.29,12.29]$ & \\
\hline Total $(95 \% \mathrm{Cl})$ & & & 138 & & & 141 & $100.0 \%$ & $2.37[-0.39,5.12]$ & \\
\hline $\begin{array}{l}\text { Heterogeneity: } \mathrm{Chi}^{2}= \\
\text { Test for overall effect: }\end{array}$ & $\begin{array}{l}09, \mathrm{df}= \\
=1.69\end{array}$ & $\begin{array}{l}3(P= \\
P=0.0\end{array}$ & $\begin{array}{l}0.55) ; \\
09)\end{array}$ & $\left.\right|^{2}=0 \%$ & & & & & $\begin{array}{ccccc}-20 & -10 & 0 & 10 & 20 \\
& H E S & \text { control gr }\end{array}$ \\
\hline
\end{tabular}

Figure 6 Forest plots of pooled estimates for the effect on hemodynamics. a) mean arterial pressure (MAP). b) heart rate (HR). Cl, confidence interval; HES, hydroxyethyl starch; IV, inverse variance.

adult patients. Given the limited number of studies enrolled in this meta-analysis, more clinical studies with larger sample sizes are needed to confirm the association between HES use and the length of ICU stay.

There are several limitations in this meta-analysis. First, the analysis is based on only 13 RCTs and some of them had a relatively small sample size of pediatric patients. Second, the control groups in these studies used multiple different fluids including fresh frozen plasma, dextran, albumin, gelatin and crystalloids, and, therefore, it is difficult to make a subgroup analysis according to the different fluids. Finally, although there is no heterogeneity between the included studies, patient characteristics including age of the enrolled children and other baseline data are different, which may affect the accuracy of the meta-analysis results.

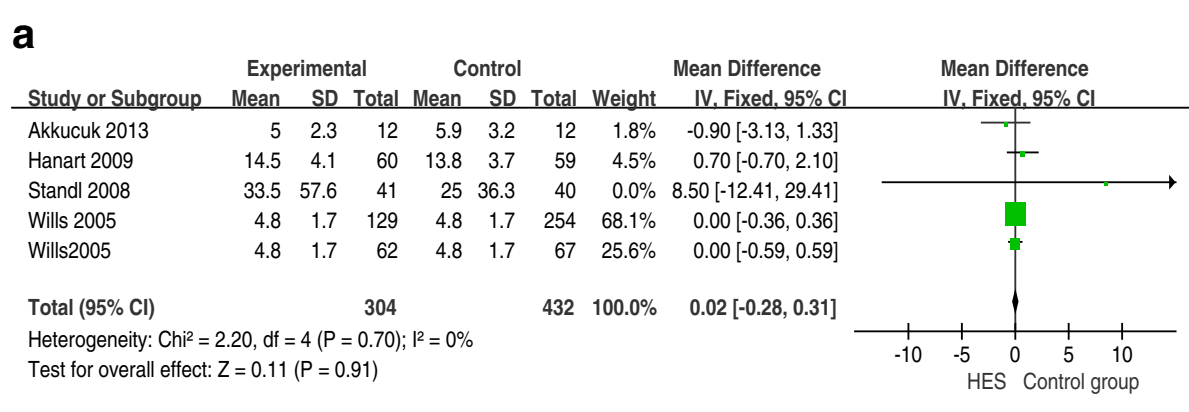

b

\begin{tabular}{|c|c|c|c|c|c|c|c|c|c|c|}
\hline \multirow[b]{2}{*}{ Study or Subgroup } & \multicolumn{3}{|c|}{ Experimental } & \multicolumn{3}{|c|}{ Control } & \multicolumn{2}{|r|}{ Mean Difference } & \multirow{2}{*}{\multicolumn{2}{|c|}{$\begin{array}{l}\text { Mean Difference } \\
\text { IV, Fixed, } 95 \% \mathrm{Cl}\end{array}$}} \\
\hline & Mean & SD & Total & Mean & SD & Total & Weight & IV, Fixed, 95\% Cl & & \\
\hline Akkucuk 2013 & 2.5 & 2.2 & 12 & 3 & 2.8 & 12 & $14.2 \%$ & $-0.50[-2.51,1.51]$ & & \\
\hline Hanart 2009 & 5.3 & 2.6 & 60 & 4 & 2 & 59 & $83.1 \%$ & $1.30[0.47,2.13]$ & & \\
\hline Standl 2008 & 7.6 & 11.5 & 41 & 9.1 & 14.2 & 40 & $1.8 \%$ & $-1.50[-7.14,4.14]$ & & \\
\hline Van Der Linden 2013 & 6.1 & 8.9 & 31 & 11.1 & 20.2 & 29 & $0.9 \%$ & $-5.00[-12.99,2.99]$ & & \\
\hline Total $(95 \% \mathrm{Cl})$ & & & 144 & & & 140 & $100.0 \%$ & $0.94[0.18,1.70]$ & & $\Delta$ \\
\hline \multicolumn{9}{|c|}{ Heterogeneity: $\mathrm{Chi}^{2}=5.52, \mathrm{df}=3(P=0.14) ;\left.\right|^{2}=46 \%$} & -10 & $\begin{array}{cccc}-5 & 0 & 5 & 10 \\
\text { HES } & \text { Control group }\end{array}$ \\
\hline
\end{tabular}

Figure 7 Forest plots of pooled estimates for the effect on the length of hospital stay and ICU. a) the length of hospital stay. b) the length of ICU stay. Cl, confidence interval; HES, hydroxyethyl starch; IV, inverse variance. 


\section{Conclusions}

Volume expansion with 6\% HES significantly decreased the platelet count and increased the length of ICU stay, and also might have an adverse effect on renal function. Therefore, HES is not recommended for use in pediatric patients before more studies confirm these results.

\section{Key messages}

- HES decreased the platelet count and increased the length of ICU stay in pediatric patients, and might have adverse effects on coagulation function.

- HES might have an adverse effect on renal function.

- HES is not recommended for use in pediatric patients before more studies confirm these results.

\section{Additional files}

\section{Additional file 1: Search strategy.}

Additional file 2: Figure S1. The funnel plot of overall mortality.

Additional file 3: Figure S2. The funnel plot of the effect on renal function. SE,standard error; $\mathrm{MD}$, mean difference.

Additional file 4: Figure S3. The funnel plot of the effect on coagulation and bleeding. a) Activated partial thromboplastin time (APTT). b) Platelet count. c) Blood loss. SE,standard error; MD,mean difference.

\section{Abbreviations}

APTT: activated partial thromboplastin time; Cl: confidence interval; HES: hydroxyethyl starch; HR: heart rate; ICU: intensive care unit; MAP: mean arterial pressure; MD: mean difference; RCT: randomized controlled trial; RR: relative risk.

\section{Competing interests}

The authors declare that they have no competing interests.

\section{Authors' contributions}

All authors participated in the study design of the research project. LL and $Y L^{*}$ (Yongyang Li) participated in screening the results, obtaining the full texts of the related studies and writing the manuscript. XX helped include RCTs and analyzed the data. BX and RR participated in making the tables and figures and statistics. YL (Yan Liu) confirmed the outcome data and assessed the study quality. BH and JZ mainly designed the research and revised the manuscript. All authors read and approved the final manuscript.

\section{Acknowledgments}

This work was supported by the Science Technology Foundation of Shanghai Jiaotong University School of Medicine (JYY1205); the Science Technology Council Foundation of Shanghai (12DZ1930404); and the National Natural Science Foundation of China $(81270003,81470390$, 81100826)

\section{Author details}

'Department of Pharmacy, Xinhua Hospital, Shanghai Jiaotong University School of Medicine, Kongjiang Road 1665, Shanghai 200092, China. ${ }^{2}$ Department of Surgery, Shanghai Jiaotong University Affiliated Sixth People's Hospital, Yishan Road 600, Shanghai 200233, China. ${ }^{3}$ Department of Epidemiology, Shanghai Jiaotong University School of Medicine, Kongjiang Road 1665, Shanghai 200092, China. ${ }^{4}$ Department of Anesthesiology and SICU, Xinhua Hospital, Shanghai Jiaotong University School of Medicine, Kongjiang Road 1665, Shanghai 200092, China.
Received: 6 July 2014 Accepted: 13 February 2015

Published online: 10 March 2015

\section{References}

1. Brunkhorst FM, Engel C, Bloos F, Meier-Hellmann A, Ragaller M, Weiler N, et al. Intensive insulin therapy and pentastarch resuscitation in severe sepsis. N Engl J Med. 2008;358:125-39.

2. Myburgh JA, Finfer S, Bellomo R, Billot L, Cass A, Gattas D, et al. Hydroxyethyl starch or saline for volume expansion in intensive care. N Engl J Med. 2012;367:1901-11.

3. Perner A, Haase N, Guttormsen AB, Tenhunen J, Klemenzson G, Aneman A, et al. Hydroxyethyl starch 130/0.42 versus Ringer's acetate in severe sepsis. N Engl J Med. 2012;367:124-34

4. Reinhart K, Perner A, Sprung CL, Jaeschke R, Schortgen F, Johan Groeneveld $A B$, et al. Consensus statement of the ESICM task force on colloid volume therapy in critically ill patients. Intensive Care Med. 2012;38:368-83.

5. Papastamelos C, Panitch HB, England SE, Allen JL. Developmental changes in chest wall compliance in infancy and early childhood. J Appl Physiol. 1995;78:179-84.

6. Senzaki H, Akagi M, Hishi T, Ishizawa A, Yanagisawa M, Masutani S, et al. Age-associated changes in arterial elastic properties in children. Eur J Pediatr. 2002;16:547-51

7. Chemla D, Hébert JL, Coirault C, Zamani K, Suard I, Colin P, et al. Total arterial compliance estimated by stroke volume-to-aortic pulse pressure ratio in humans. Am J Physiol. 1998;274:H500-5.

8. Moher D, Liberati A, Tetzlaff J, Altman DG. Preferred reporting items for systematic reviews and meta-analyses: the PRISMA statement. Ann Intern Med. 2009;151:264-9.

9. Dias S, Sutton AJ, Ades AE, Welton NJ. Evidence synthesis for decision making 2: a generalized linear modeling framework for pairwise and network meta-analysis of randomized controlled trials. Med Decis Making. 2013;33:607-17.

10. Jadad AR, Moore RA, Carroll D, Jenkinson C, Reynolds DJ, Gavaghan DJ, et al. Assessing the quality of reports of randomized clinical trials: is blinding necessary? Control Clin Trials. 1996;17:1-12.

11. Higgins JP, Altman DG, Gøtzsche $P C$, Jüni $P$, Moher $D$, Oxman AD, et al. The Cochrane Collaboration's tool for assessing risk of bias in randomised trials. BMJ. 2011;18:343-52.

12. Hozo SP, Djulbegovic B, Hozo I. Estimating the mean and variance from the median, range, and the size of a sample. BMC Med Res Methodol. 2005;5:13.

13. Higgins JP, Thompson SG. Quantifying heterogeneity in a meta-analysis. Stat Med. 2002;21:1539-58.

14. Liet JM, Kuster A, Denizot S, Caillaux-Varin G, Gras-Leguen C, Rozé JC. Effects of hydroxyethyl starch on cardiac output in hypotensive neonates: a comparison with isotonic saline and 5\% albumin. Acta Pediatrica. 2006;95:555-60.

15. Standl T, Lochbuehler H, Galli C, Reich A, Dietrich G, Hagemann H. HES 130/0.4 (Voluven) or human albumin in children younger than $2 \mathrm{yr}$ undergoing non-cardiac surgery. A prospective, randomized, open label, multicentre trial. Eur J Anaesthesiol. 2008:25:437-45.

16. Akech SO, Jemutai J, Timbwa M, Kivaya E, Boga M, Fegan G, et al. Phase II trial on the use of Dextran 70 or starch for supportive therapy in Kenyan children with severe malaria. Crit Care Med. 2010;38:1630-6.

17. Van der Linden $P$, De Villé $A$, Hofer A, Heschl M, Gombotz H. Six percent hydroxyethyl starch 130/0.4 (Voluven ${ }^{\oplus}$ ) versus 5\% human serum albumin for volume replacement therapy during elective open-heart surgery in pediatric patients. Anesthesiology. 2013;119:1296-309.

18. Liet JM, Bellouin AS, Boscher C, Lejus C, Rozé JC. Plasma volume expansion by medium molecular weight hydroxyethyl starch in neonates: a pilot study. Pediatr Crit Care Med. 2003;4:305-7

19. Hanart C, Khalife M, De Villé A, Otte F, De Hert S, Van der Linden P. Perioperative volume replacement in children undergoing cardiac surgery: albumin versus hydroxyethyl starch 130/0.4. Crit Care Med. 2009;37:696-701.

20. Akkucuk FG, Kanbak M, Ayhan B, Celebioglu B, Aypar U. The effect of HES (130/0.4) usage as the priming solution on renal function in children undergoing cardiac surgery. Ren Fail. 2013;35:210-5.

21. Chong Sung K, Kum Suk P, Mi Ja Y, Kyoung OK. Effects of intravascular volume therapy using hydroxyethyl starch (130/0.4) on post-operative bleeding and transfusion requirements in children undergoing cardiac surgery: a randomized clinical trial. Acta Anaesthesiol Scand. 2006;50:108-11. 
22. Haas T, Preinreich A, Oswald E, Pajk W, Berger J, Kuehbacher G, et al. Effects of albumin $5 \%$ and artificial colloids on clot formation in small infants. Anaesthesia. 2007:62:1000-7.

23. Wills BA, Nguyen MD, Ha TL, Dong TH, Tran TN, Le TT, et al. Comparison of three fluid solutions for resuscitation in dengue shock syndrome. N Engl J Med. 2005;353:877-89.

24. Sahoo TK, Chauhan S, Sahu M, Bisoi A, Kiran U. Effects of hemodilution on outcome after modified Blalock-Taussig shunt operation in children with cyanotic congenital heart disease. J Cardiothorac Vasc Anesth. 2007;21:179-83

25. Osthaus WA, Witt L, Johanning K, Boethig D, Winterhalter M, Huber D, et al. Equal effects of gelatin and hydroxyethyl starch (6\% HES 130/0.42) on modified thrombelastography in children. Acta Anaesthesiol Scand. 2009;53:305-10.

26. Witt L, Osthaus WA, Jüttner B, Heimbucher C, Sümpelmann R. Alteration of anion gap and strong ion difference caused by hydroxyethyl starch 6\% (130/0.42) and gelatin 4\% in children. Paediatr Anaesth. 2008:18:934-9.

27. Maitland K, Pamba A, English M, Peshu N, Marsh K, Newton C, et al. Randomized trial of volume expansion with albumin or saline in children with severe malaria: preliminary evidence of albumin benefit. Clin Infect Dis. 2005;40:538-45.

28. Maitland K, Pamba A, English M, Peshu N, Levin M, Marsh K, et al. Pre-transfusion management of children with severe malarial anaemia: a randomised controlled trial of intravascular volume expansion. Br J Haematol. 2005;128:393-400.

29. Kalayanarooj S. Choice of colloidal solutions in denque hemorrhagic fever patients. J Med Assoc Thai. 2008;91:597-103.

30. Cochrane Injuries Group Albumin Reviewers. Human albumin administration in critically ill patients: systematic review of randomised controlled trials. BMJ. 1998;317:235-40.

31. Vincent $J L$, Sakr $Y$, Sprung $C L$, Ranieri VM, Reinhart $K$, Gerlach $H$, et al. Sepsis in European intensive care units: results of the SOAP study. Crit Care Med. 2006:34:344-53.

32. Hartog C, Reinhart K. CONTRA: hydroxyethyl starch solutions are unsafe in critically ill patients. Intensive Care Med. 2009;35:1337-42.

33. Hartog CS, Bauer M, Reinhart K. The efficacy and safety of colloid resuscitation in the critically ill. Anesth Analg. 2011;112:156-64.

34. Haase N, Perner A, Hennings LI, Siegemund M, Lauridsen B, Wetterslev M, et al. Hydroxyethyl starch 130/0.38-0.45 versus crystalloid or albumin inpatients with sepsis: systematic review with meta-analysis and trial sequential analysis. BMJ. 2013;346:f839.

35. Sander O, Reinhart K, Meier-Helmann A. Equivalence of hydroxyethy starch HES 130/0.4 and HES 200/0.5 for perioperative volume replacement in major gynaecological surgery. Acta Anaesthesiol Scand. 2003;47:1151-8.

36. Miller BE, Guzzetta NA, Tosone SR, Levy JH. Rapid evaluation of coagulopathies after cardiopulmonary bypass in children using modified thromboelastography. Anesth Analg. 2000:90:1324-30.

37. Sniecinski RM, Levy JH. Bleeding and management of coagulopathy. J Thorac Cardiovasc Surg. 2011;142:662-7.

38. Paparella D, Brister SJ, Buchanan MR. Coagulation disorders of cardiopulmonary bypass: a review. Intensive Care Med. 2004;30:1873-81.

39. Wilkes MM, Navickis RJ, Sibbald WJ. Albumin versus hydroxyethyl starch in cardiopulmonary bypass surgery: a meta-analysis of postoperative bleeding. Ann Thorac Surg. 2001;72:527-33.

40. Leberle R, Ernstberger A, Loibl M, Merkl J, Bunz M, Creutzenberg M, et al. Association of high volumes of hydroxyethyl starch with acute kidney injury in elderly trauma patients. Injury. 2014;1383:413-6.

41. Hamaji A, Hajjar L, Caiero M, Almeida J, Nakamura RE, Osawa EA, et al. Volume replacement therapy during hip arthroplasty using hydroxyethyl starch (130/0.4) compared to lactated Ringer decreases allogeneic blood transfusion and postoperative infection. Braz J Anesthesiol. 2013;63:27-35.

42. Serpa Neto A, Veelo DP, Peireira VG, de Assuncao MS, Manetta JA, Esposito DC, et al. Volume expansion with hydroxyethyl starches in patients with sepsis is associated with an increased incidence of acute kidney injury and use of renal replacement therapy: a systematic review and meta-analysis of the literature. J Crit Care. 2014;29:185.e1-7.

\section{Submit your next manuscript to BioMed Central and take full advantage of:}

- Convenient online submission

- Thorough peer review

- No space constraints or color figure charges

- Immediate publication on acceptance

- Inclusion in PubMed, CAS, Scopus and Google Scholar

- Research which is freely available for redistribution

Submit your manuscript at www.biomedcentral.com/submit 